\title{
MILLENNIALS AND CAR OWNERSHIP: LESS MONEY, FEWER CARS
}

Submitted Transport Policy

Original Submission: November 20, 2015

Revised Submission: April 25, 2016

Revised Submission: August 10, 2016

Nicholas J. Klein $^{\mathrm{a}}$ and Michael J. Smart ${ }^{\mathrm{b}}$

a.

Corresponding author

n.klein@columbia.edu

Visiting Assistant Professor

Graduate School of Architecture, Planning and Preservation

Avery Hall, Columbia University

Avery Hall

Columbia University,

New York, NY 10027

b.

mike.smart@rutgers.edu

Assistant Professor

Edward J. Bloustein School of Planning and Public Policy

Rutgers, the State University of New Jersey

Room 535, Civic Square Building

33 Livingston Ave.

New Brunswick, NJ 08901 


\section{INTRODUCTION}

Since the mid-2000s, car use and drivers licensing has been declining in the United States and peer countries, particularly among the young (Millard-Ball and Schipper, 2011; Kuhnimhof et al., 2013; Metz, 2013). Less attention has been paid to changing rates of car ownership, an important driver of car use. In this article, we turn our attention to car ownership, and explore just what lurks behind the dramatic decline in car ownership among young people in the U.S.

Who exactly is giving up their cars and why? One explanation posits that changing preferences for urban living and transit use and an increasing environmental consciousness could be leading to a decline in auto ownership, particularly among the young. An alternative explanation suggests that economic factors are the cause of this decline. For planners, the different explanations point to different policies to balance welfare and environmental sustainability.

We use the Panel Study of Income Dynamics (PSID) to examine recent changes in auto ownership among U.S. families, focusing on generational differences. The PSID has not been used to examine generational shifts in travel patterns before, to our knowledge. As a panel data set, the PSID is uniquely suited to this question, tracking the same people across more than a decade, separating out how changes in their economic, demographic, and geographic characteristics influence the decision to own one or more cars. We include eight waves of this large national panel survey, from 1999 through 2013.

First, we describe the changing nature of car ownership among different birth cohorts. We then use the data to run a series of panel regressions that model the changes 
in the ratio of cars to adults within families across successive waves of the PSID. We examine the influence of factors such as age, family size, employment status, income, wealth and the availability of high-quality public transportation.

We find that today's young adults do own fewer cars than previous generations did when they were young. However, when we control for whether young adults have become economically independent from their parents, i.e. left the nest, we find that economically independent young adults own slightly more cars than we would expect, given their low incomes and wealth. This suggests that planners should temper their enthusiasm about "peak car," as this may largely be a manifestation of economic factors that may reverse in coming years. Other factors, such as delayed marriage, may continue into the future.

\section{CHANGING TRAVEL BEHAVIOR AMONG YOUNG ADULTS}

Americans have been driving less in recent years. This has surprised many transportation experts, who for generations have witnessed a consistent increase in the use of the automobile (Jones, 2008). Millennials — those born in the 1980s and 1990s - in particular own fewer cars, drive less, and are less likely to be licensed drivers than were the generations that preceded them (Ralph, 2015; Polzin et al., 2014; McDonald, 2015). Research in a number of contexts across the "Global North" has found that these trends are not unique to the U.S. (Delbosc, 2016; Delbosc and Currie, 2013; Goodwin, 2012; Kuhnimhof et al., 2013, 2012; Millard-Ball and Schipper, 2011). A flurry of research and speculation has followed.

The research has generally followed two lines of investigation: changing lifestyles and preferences toward the automobile on the one hand, and economic explanations for 
the decline in driving on the other. In a recent study using the 1995, 2001, and 2009 National Household Travel Surveys, McDonald (2015) uses this framework to assess trends in licensing, auto trip frequency, and daily automobile miles traveled among age groups. She finds that the bulk of the decline in travel can be attributed to temporal trends that affect all age groups, though lifestyle-related demographic shifts play a large role in explaining the changes among people aged 25 to 30 years. Ralph (2015), using the same datasets, finds similar outcomes but emphasizes the worsening economic status of young people as the primary reason for decreased travel. Blumenberg et al. (2012), again using the same data, also find support for economic explanations for the car-light lives of today's youth, though there are some unaccounted-for differences between generations. And a recent report from the United States Federal Reserve found that the decline in car purchases among the young was likely due to shifting economic circumstances rather than preferences (Kurz et al., 2016).

The social and cultural preference theory suggests that Millenials desire to live in dense areas with access to high-quality public transportaiton, and their adoption of new information technologies has further acted as a catalyist for changing travel behavior (van Wee, 2015). For people without cars or with limited access to cars, new transportation services have increased the supply and awareness of additional travel options, such as taxi services, shared ride services, and improved real-time transit information. The array of new technologies enable the substitution of online activities for social, work and shopping related travel. Among the evidence for a changing cultural landscape is a recent TransitCenter survey, which found that Millennials view public transportation much more favorably than do older Americans, though this study only compared generations at 
one time, and thus does not answer the pressing question of whether today's young people are different from yesterday's young people (TransitCenter, 2014). Similarly, a study by the U.S. Public Interest Research Group suggests that, while economic factors may play a role, Millennials's decreased usage of the automobile can be attributed to factors such as a preference for urban living, the increased usage of mobile devices, and the like (USPIRG Education Fund and Frontier Group, 2014).

Others take a more skeptical view about the new technologies decreasing travel, stressing that new communications technologies can create new travel demand as well as substitute for it (Mokhtarian, 2002, 2009; Dal Fiore et al., 2014). One study using the NHTS datasets finds that increased use of the internet leads to more travel, not less (Blumenberg et al., 2012).

Our study fills a gap in the literature in several ways. First, we focus on car ownership, an important and costly determinant of travel mode choice. We also include a metric of the quality of transit service in the individual's home census tract, a variable missing in prior analyses. More importantly, by using a panel dataset, we improve on existing studies — which have relied on cross-sectional analyses - by following the same individuals across more than a decade. Our dataset spans periods before and after the start of the decline in driving, which began sometime in the mid-2000s, roughly the midpoint of our panel. Finally, by using detailed, geo-coded microdata on individuals and their families, we can examine how generations' transportation and location choices have changed over time, disentangling which factors play a large role, and which a smaller role. 


\section{RESEARCH APPROACH}

We use the Panel Study of Income Dynamics (PSID) to examine auto ownership within U.S. families over time, focusing on differences between the Millennial generation and several generations that preceded them (Panel Study of Income Dynamics, restricted use data, 2014). The PSID began in 1968 and has been following the same families ever since (McGonagle et al., 2012). The first wave included roughly 5,000 families $(18,000$ individuals) and recent waves have about 9,000 families (22,000 individuals). The sample has increased through the expansion of families via cohabitation, births and adoptions, as well as the additions of a Latino subsample in the early 1990s and an immigrant sample in the late 1990s (McGonagle et al., 2012). In our analysis, we use a restricted version of the dataset that identifies the census tract where each individual resides. This allows us to assess the effect of local factors that may relate to the decision to own a vehicle.

We include eight waves of the panel survey collected biennially from 1999 through 2013. We focus on these waves both to capture recent changes in auto ownership (both before and after the reversal of the growth in driving) and because earlier waves did not include questions about auto ownership or transit expenditures (though the survey did include questions about auto ownership prior to 1986). We use PSID-supplied weights to account for oversampling of some groups, as well as differential attrition from the sample over time; when using these weights, the survey is representative (Fitzgerald, 2011).

The primary sampling unit in the PSID is the "family unit," not the household. The PSID defines a family as any number of within-household arrangements, including singles living alone. Only when a person moves out of their family unit to live elsewhere and are "economically independent," are they treated as separate family units. College 
students (and persons living in other institutions) are not considered separate family units, unless they are economically independent, even when they live apart from the rest of their family unit.

We model the number of cars owned by each family with a Poisson panel regression. To account for resource sharing and competition within the family, we use the number of adults in the family as an exposure measure in our model. In the following sections, we present the model results for our preferred model, a random-effects models, and then discuss the findings from a series of fixed-effects models. For our preferred model, we chose a random-effects model for two reasons. First, we wanted to include a variable indicating that the respondent is in the millennial cohort but since this does not vary for individuals over time, it cannot be included directly in a fixed-effects model. Second, the fixed effect model drops respondents who have no change in car availability over time, including over 700 individuals who have no car in any wave, a group we believe is important. While a Hausman test comparing the random- and fixed-effects models was significant, the magnitude and significance of the coefficients were largely the same in both models. After we present the random-effects model, we briefly discuss several fixed-effect model specifications (and some other alternative specifications). Since we cannot directly include millennial status in the fixed-effect models, we ran segmented models for Millennials and earlier generations and compared the model coefficients.

We also include other attributes about the individual, the family and the neighborhood in which they live. We include both age and its squared term to account for non-linear trends in car ownership across lifecycles, with people in the middle of their 
adult years owning more cars per adult than those who are younger or older. We restrict our sample to individuals aged 18 to 65 . We include the number of workers and children in the family, the race and ethnicity of the head of the family, total family income (logtransformed) and family wealth (this variable is included in the PSID dataset and is constructed from assets, such as savings, real estate, stocks and so forth, minus debts). The PSID only identifies the race of the head and spouse, so we assign all family members the race of the head. Our geographic variables are population density (measured in thousands of persons per square mile) and whether they live in a rural area (from the 2005-2009 and 2009-2013 American Community Survey 5-Year Estimates), and a measure of transit service.

Our measure of transit service is access to jobs on public transportation from the home census tract. We obtained this data from two sources: Transit and Jobs in Metropolitan America (Tomer et al., 2011) and Access Across America: Transit 2014 (Owen and Levinson, 2014). Each of these sources provides only partial coverage for the U.S., so we created a composite measure of the total number of jobs available within 30 minutes by transit. Where both datasets provided estimates, we averaged the two (they are highly correlated at $\mathrm{r}=0.92$ where they overlap); otherwise, we used whichever was available. We standardize our metric by metropolitan area as z-scores (standard deviations above or below the regional mean).

There are some limitations to our transit data. The composite measure covers just over half of the observations in our dataset. In our preferred models, we include a dummy variable to indicate census tracts for which we have no transit information. We suspect that missing transit data largely, but not entirely, proxies for places with no transit 
service. We estimated several alternative models using multiple imputation methods to estimate transit service for these tracts. We also estimated a model that excluded all tracts missing transit data. In each case, the model coefficients were consistent in direction, though the magnitude varied somewhat. A second limitation is that our transit access metric does not vary over time, thus ignoring changes to transit service and the spatial distribution of jobs. We expect this contributes some error to our models, though both the general patterns of transit service and the locations of jobs are unlikely to have changed drastically during our study period.

\section{CHANGING CAR OWNERSHIP AMONG U.S. FAMILIES}

First, we describe the generational trends in car ownership and other related variables. These trends suggest dramatic changes in car ownership, transit use and population density across generations. Second, we summarize the data from the PSID that we use in our model. Third, we present the results of the random-effects Poisson regression.

\subsection{Generational Trends}

Compared to earlier generations, Millennials have lower levels of car ownership, on average, as shown in Figure 1. This figure charts the ratio of cars to adults in PSID families plotted as a function of the age for all individuals. This figure, and those that follow in this section, show differences among cohorts and the trends as the respondents age over the eight panel waves from 1999 through 2013. Thus, a given respondent might be represented by eight data points aggregated into the generational lines in the chart. 
Additionally, the charts are constructed using all respondents in the sample, not just the head of each family. As a result, families are represented multiple times on the chart for each family member. Using only the family heads would limit our ability to observe the experiences of Millennials in the data set since it would only include those who have split off from their family unit by moving out and becoming economically independent.

Figure 1 shows that Millennials have lower rates of car ownership than the cohort that came before them when they were the same age. While this youngest birth cohort never has more than 0.9 cars per adult in the family, those born in the $1950 \mathrm{~s}, 60 \mathrm{~s}, 70 \mathrm{~s}$, consistently have more cars per adult. The clear outliers are those born in the 1940s, whose level of car ownership far outstrips that of other generations.

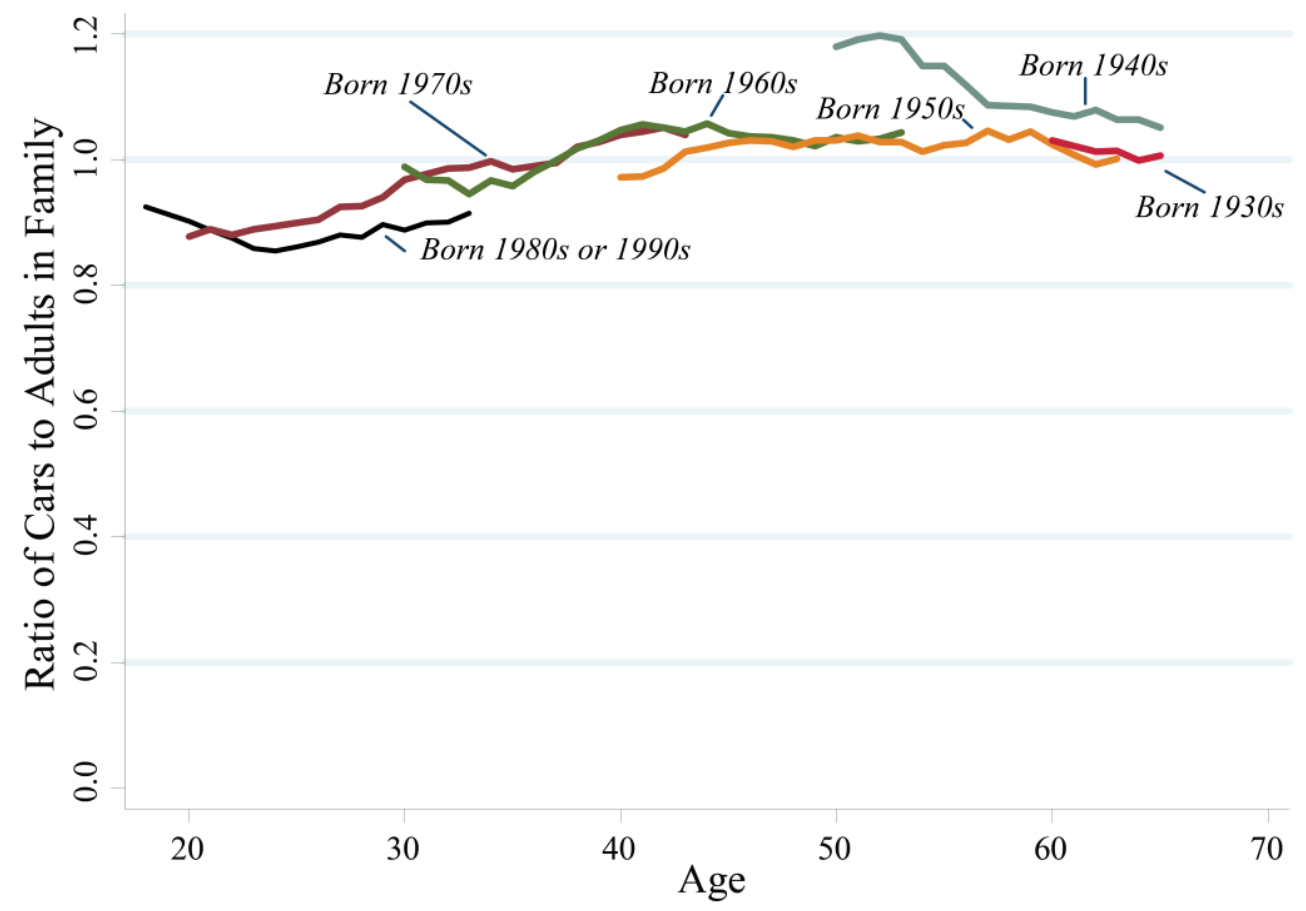

Figure 1 Ratio of Cars to Adults in an Individual's Family by Birth Cohort and Age, PSID 1999-2013

To highlight the differences within the youngest cohort, we categorized Millennials as either economically dependent or independent. The latter group of 
Millennials represents those who have moved out and started their own family unit (including those living alone). Figure 2 charts the changing classification of Millennials in the survey as they age across the eight waves of data. As expected, Millennials are more likely to be economically dependent when they are younger and more likely to be economically independent beginning in their mid-20s. In addition, latter waves of our panel data include far more Millennials than the earlier waves. This is a function of survey respondents born in the 1980s and 1990s turning 18 and being included in our analysis sample (at the other end of the spectrum, those born in the 1930s and 1940s age out of sample when they turn 66). In the 1999 wave, our sample includes just over 700 Millennials while there are over 6,500 in the 2013 wave.
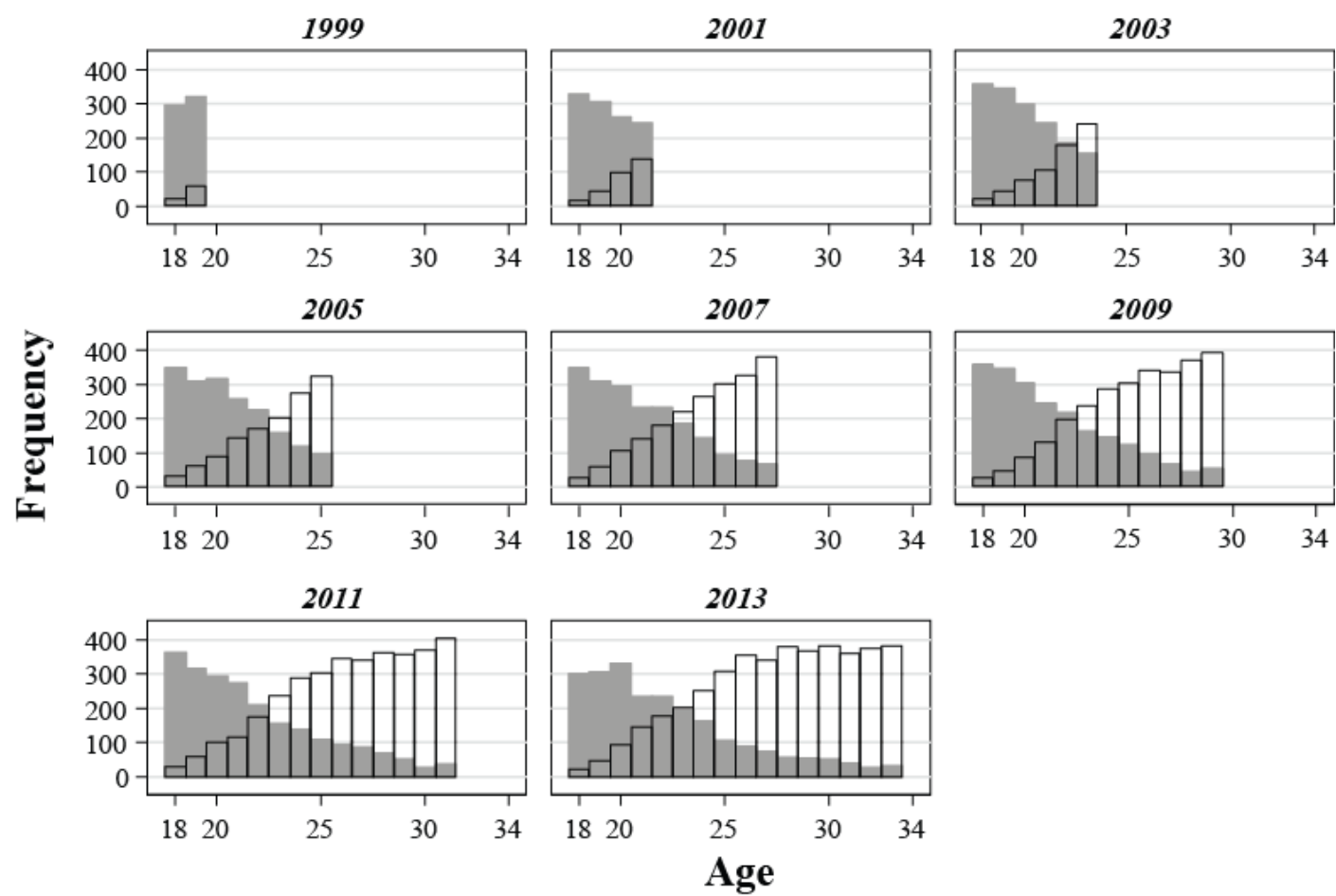

Econ. Dependent Millennials

Econ. Independent Millennials

Figure 2 Number of Dependent and Independent Millennials by Wave, PSID 19992013 
How different are economically dependent and independent Millennials? Figure 3 separates these two groups of Millennials to show their different family-level rates of cars per adult as they age, along with the older cohorts. Younger economically independent Millennials own very few cars but, as they age, their level of car ownership approaches that of the cohort that precedes them. Economically dependent Millennials start with a higher level of auto ownership that decreases as they age.

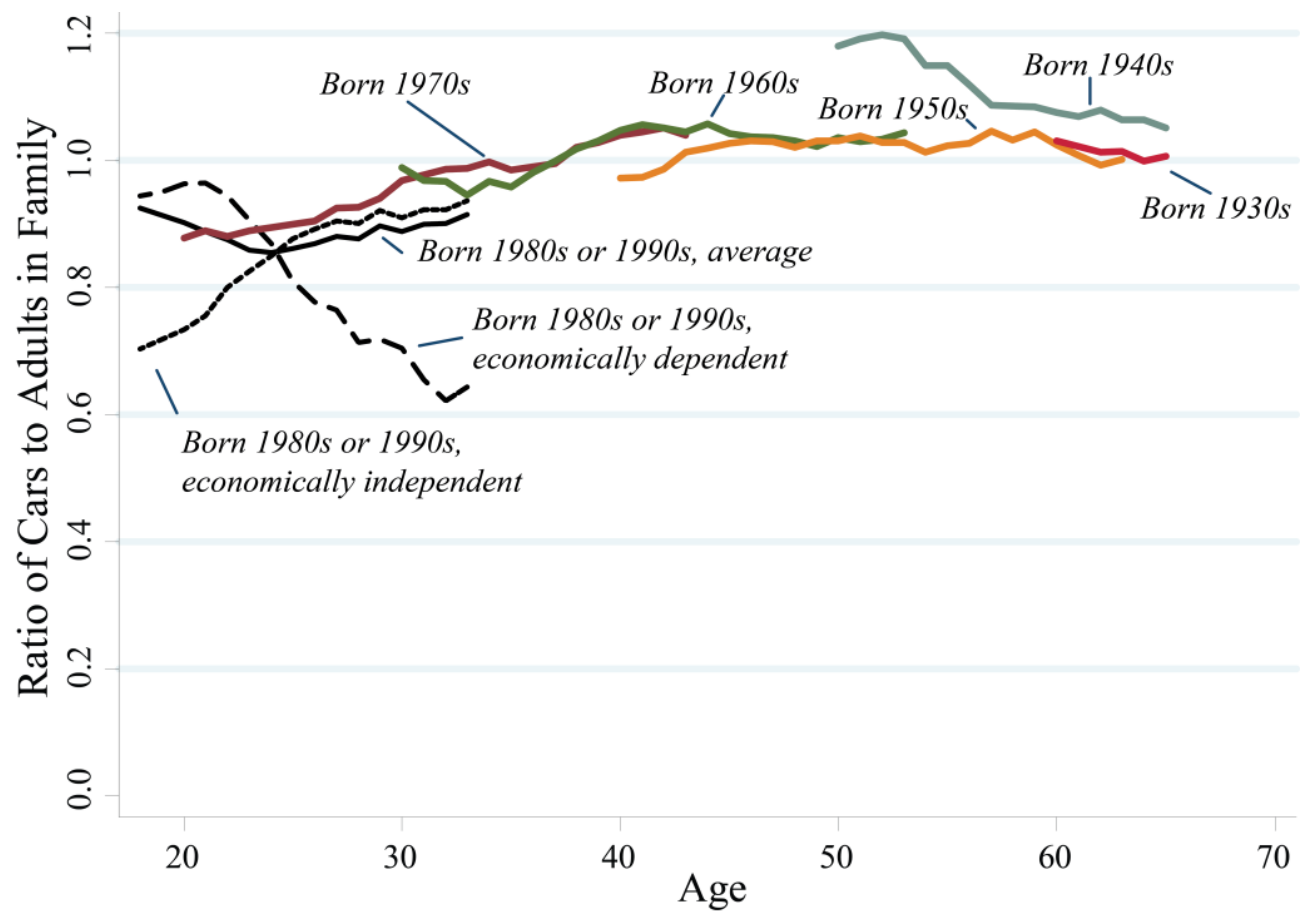

Figure 3 Ratio of Cars to Adults in an Individual's Family by Birth Cohort and Age, including Economically Dependent and Independent Millennials, PSID 1999-2013

Might the nature of economically dependent and independent Millennials change as they age? We investigated this further and found that those who are economically dependent in their mid-to-late 20 s and early 30 s are likely to remain dependent on their parents, particularly if they do not have access to a car. We suspect that these adult dependent Millennials represent a particular set of individuals who are tied to the parental 
home. This long-term dependency may be the result of long-term economic insecurity, health, or other factors, though we cannot directly test these hypotheses.

In addition to generational differences in car ownership rates, the youngest cohort is more likely to live in dense areas than are all previous birth cohorts (Figure 4). This is consistent with recent work by Myers, who adds a caution that the number of Millennials living in cities is likely to decline in the coming years as the largest cohort of Millennials turned 25 in 2015, and this group is likely to begin settling in the suburbs in greater numbers (Myers, 2016). Again, we separate economically dependent and independent Millennials and observe large differences between the two. Above 20 years of age, independent Millennials live in areas with higher population density. We contrast Millennials with those born in the 1970s, who rapidly moved to less-dense areas as they entered their 30s, dropping from above 6,000 persons per square mile when they were in their late 20 s to roughly 4,000 in their late 30 s. In this, the 1970 s cohort mimics the generation that preceded them (born in the 1960s), though the 1970s cohort began its move to less-dense areas sooner. Millennials, on the other hand, have remained in denser areas as they enter their 30s. Among those born in the 1970s, the trend may now be reversing; we note a strong upward trend in density among that cohort in recent years. 


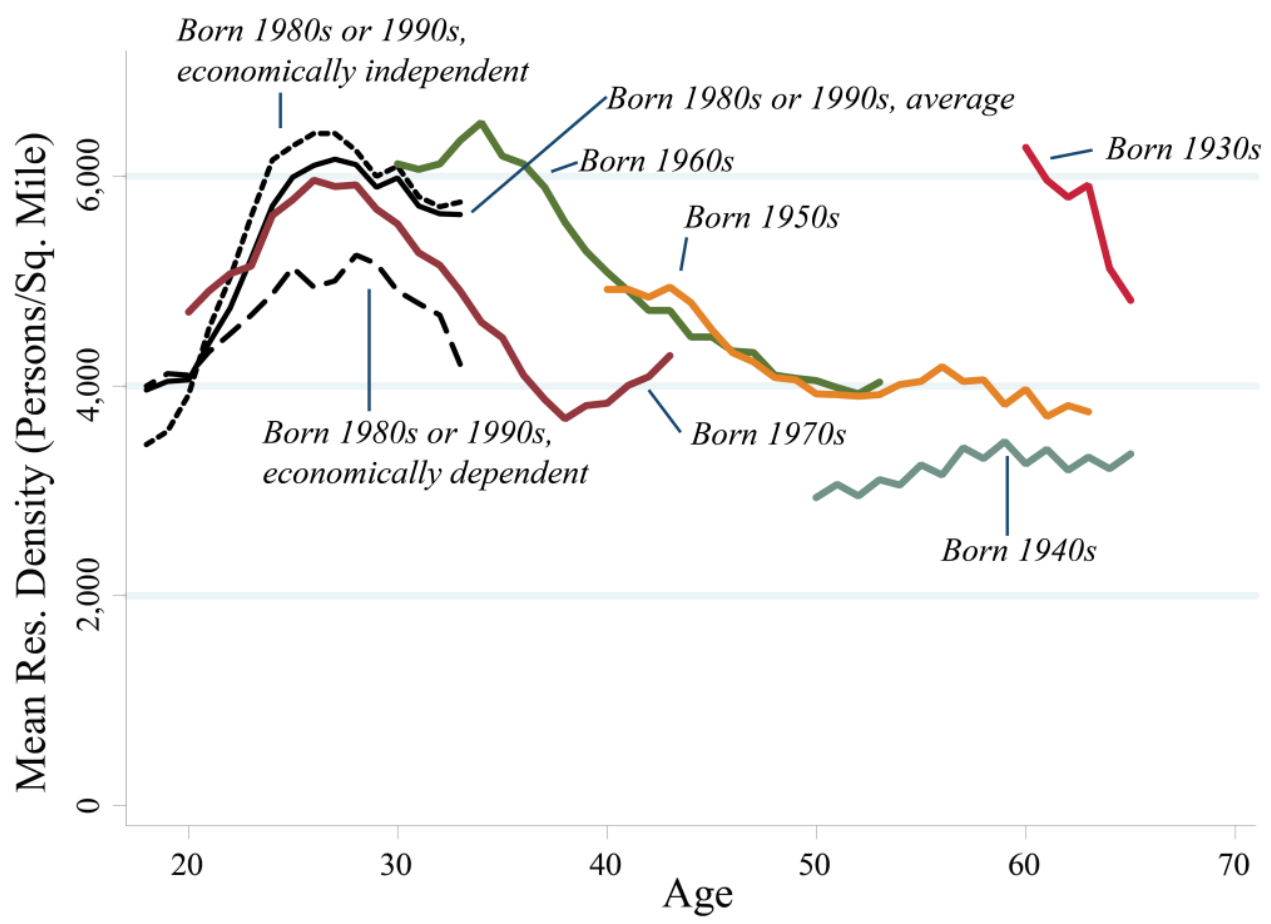

\section{Figure 4 Residential Densities of an Individual's Home Census Tract by Birth Cohort and Age, PSID 1999-2013}

Millennials are also much more likely to live in transit-rich neighborhoods. Figure 5 shows the mean of transit access to jobs. This is measured as a regionally-standardized Z-score (standard deviations from the regional mean) of the number of jobs reachable in 30 minutes on transit from the home census tract. Economically independent Millennials' transit access is much higher than that of the generation that preceded it, peaking at 0.3 standard deviations above the regional average in their mid-20s, though their access to jobs via transit declines steeply in their late 20 s and early 30 s. Economically dependent Millennials' access to transit is considerably lower, and declines sharply in later ages. Again, we see that those born in the 1970s have begun, in recent years, to move to areas with more transit access. Among other groups, the trend is declining, suggesting relocation over time to neighborhoods that have less access to transit. 


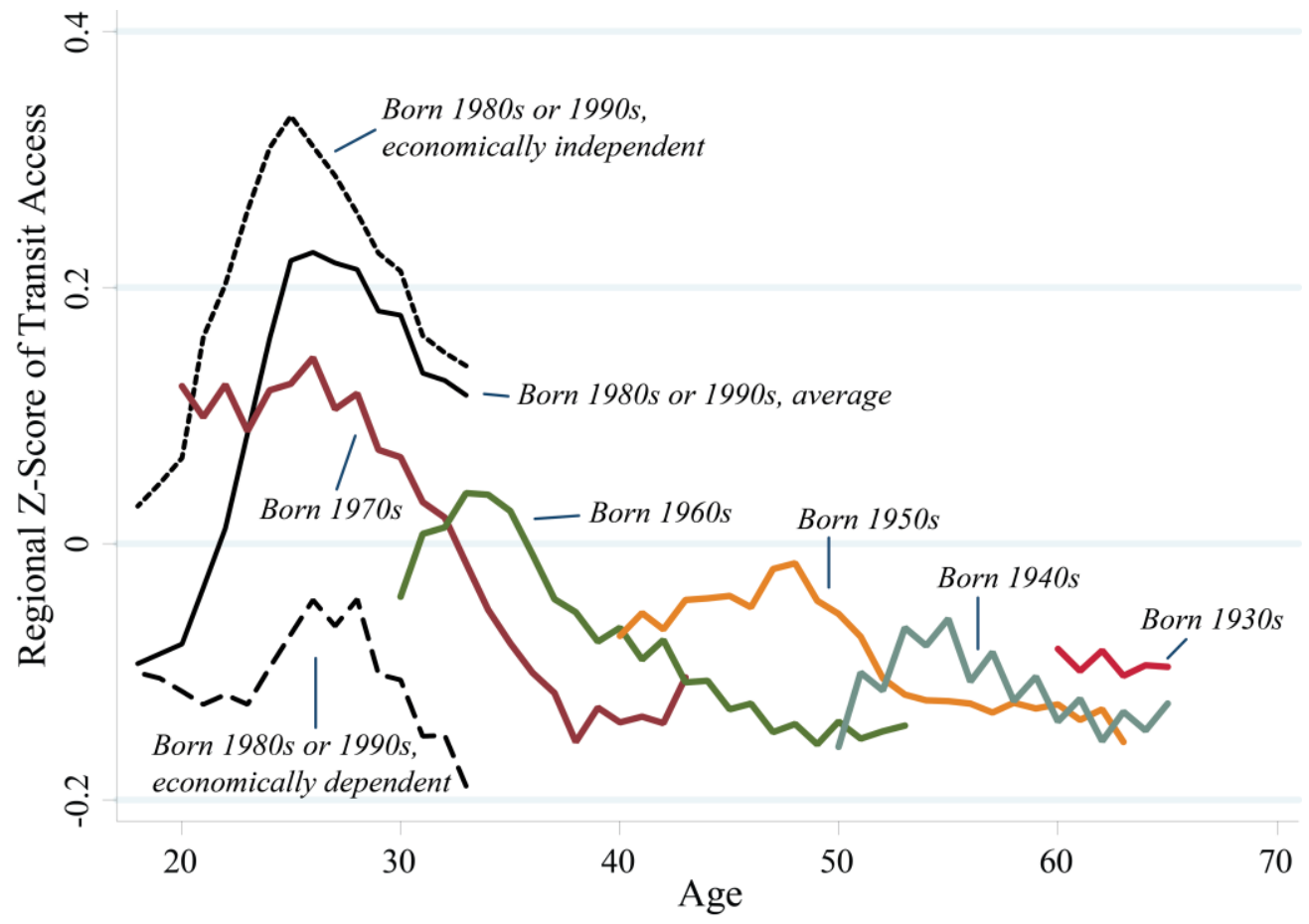

Figure 5 Transit Access to Jobs in an Individual's Family by Birth Cohort and Age, PSID 1999-2013

Millennials also had higher expenditures on public transportation than previous generations. This cohort spent, on average, $\$ 47.50$ per adult per year, peaking in their late 20s (Figure 6). But once again, there are large differences between the economically dependent and independent Millennials; the latter spend much more on transit, at every age, than the former. And previous generations spent less, about $\$ 34.50$ on average, though there is no consistent pattern across the older cohorts with respect to age. (For our analysis of transit expenditures, we restricted our sample to the 2003 and later panels since the PSID altered the way the question was asked between 2001 and 2003. In our sample, the mean expenditure in 2003 is roughly double the 2001 expenditure). The increased spending on transit over time likely results from two separate phenomena. On the one hand, the percentage of individuals in the PSID spending any money on transit has increased in recent years, and this is particularly true for Millennials (results not 
shown here). At the same time, transit fares have become more expensive in recent years, increasing an average of 46 percent between 2001 and 2013, somewhat faster than the 32 percent domestic rate of inflation over the same period (U.S. Department of Transportation, 2015, Table 3-18).

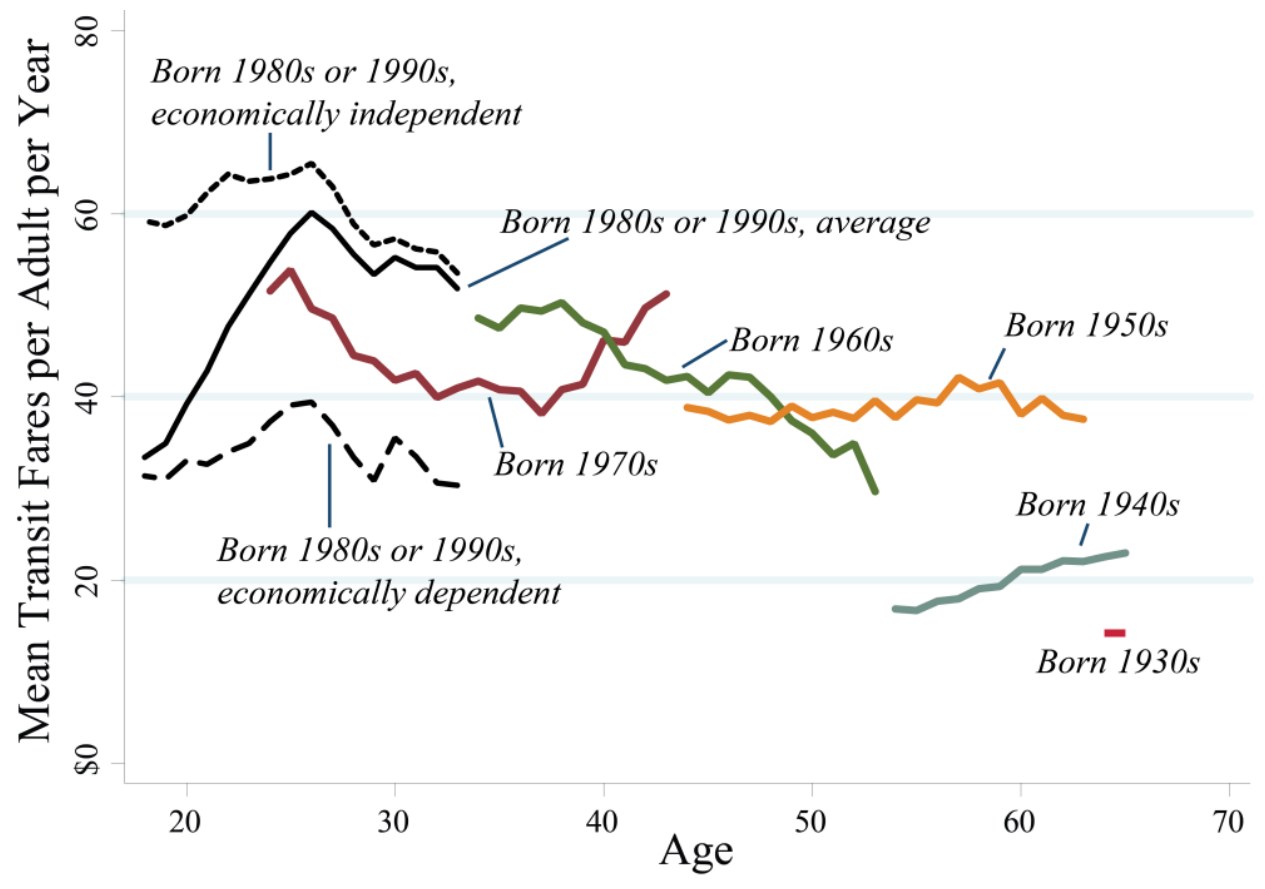

Figure 6 Spending on Transit Fares per Adult in an Individual's Family by Birth Cohort and Age, Inflation-Adjusted to 2013 \$, PSID 2003-2013

\subsection{Car ownership among Millennials}

Millennials are quite different from earlier generations across a broad range of measures that might influence auto ownership and travel behavior. Table 1 summarizes many of these attributes, which we include in our models below, and adds to the evidence that Millennials own fewer cars than older generations do. Economically independent Millennials live in smaller households, and all Millennials are more racially and ethnically diverse and have considerably lower family incomes. Independent Millennials are also far more likely to be low-wealth than are older generations. Their geographic 
characteristics are also quite different from those of older generations; independent Millennials live in places that are much denser, and have on average twice the level of transit access to jobs as do older generations. We expect that many of these variablesparticularly income, wealth, and geographic factors-will help explain many of the differences in car ownership across generations.

We hypothesize that these economic, geographic and family-level differences between Millennials and older cohorts account for the differences in auto ownership. To explore this possibility, we estimate a series of Poisson regression models to test whether the lower levels of automobile ownership among Millennials can be explained by broader socio-economic factors (lower incomes and wealth, along with smaller families), by geographic factors (living in high-density, transit rich places), or both. We examine whether these relationships hold for both economically independent and dependent Millennials. We build our preferred model in stages. In each model, we include our variables of interest—whether the respondent is a Millennial—and if so, whether he or she is economically independent. We also include dummy variables indicating the panel wave year to account for temporal trends affecting everyone. In the next models, we substitute in suites of variables to test the effect of each group of variables. The final model includes all the independent variables. 
Table 1 Descriptive statistics for Millennials and older cohorts, PSID 1999-2013

\begin{tabular}{|c|c|c|c|c|c|}
\hline & \multirow{2}{*}{$\begin{array}{c}\text { Born before } \\
1980\end{array}$} & \multicolumn{4}{|c|}{ Born in 1980 s and 1990 s } \\
\hline & & \multicolumn{2}{|c|}{$\begin{array}{c}\text { Economically } \\
\text { Dependent }\end{array}$} & \multicolumn{2}{|c|}{$\begin{array}{l}\text { Economically } \\
\text { Independent }\end{array}$} \\
\hline Num. of observations & 80,743 & 13,961 & & 14,807 & \\
\hline Num. adults in family & 2.06 & 2.92 & $* * *$ & 1.68 & $* * *$ \\
\hline Num. cars & 2.01 & 2.48 & $* * *$ & 1.44 & $* * *$ \\
\hline Ratio of cars to adults & 1.01 & 0.89 & $* * *$ & 0.86 & $* * *$ \\
\hline Age (mean) & 44.8 & 21.0 & $* * *$ & 25.6 & $* * *$ \\
\hline \multicolumn{6}{|l|}{ Race and ethnicity of family head } \\
\hline Non-Hispanic white & $74 \%$ & $61 \%$ & $* * *$ & $68 \%$ & $* * *$ \\
\hline Non-Hispanic black & $13 \%$ & $19 \%$ & $* * *$ & $16 \%$ & $* * *$ \\
\hline Non-Hispanic Asian & $2 \%$ & $3 \%$ & $* * *$ & $1 \%$ & $* * *$ \\
\hline Non-Hispanic other & $1 \%$ & $1 \%$ & & $2 \%$ & $* * *$ \\
\hline Hispanic/Latino & $9 \%$ & $14 \%$ & $* * *$ & $13 \%$ & $* * *$ \\
\hline Total family income (mean) & 101,014 & 112,734 & $* * *$ & 53,151 & $* * *$ \\
\hline Total family income (median) & 76,272 & 82,002 & & 43,496 & $* * *$ \\
\hline Num. employed family members & 1.55 & 2.07 & $* * *$ & 1.31 & $* * *$ \\
\hline Num. of children in family & 0.82 & 0.80 & & 0.82 & \\
\hline \multicolumn{6}{|l|}{ Wealth quintiles } \\
\hline 1st quintile & $16 \%$ & $17 \%$ & $*$ & $40 \%$ & $* * *$ \\
\hline 2nd quintile & $19 \%$ & $18 \%$ & & $36 \%$ & $* * *$ \\
\hline 3rd quintile & $22 \%$ & $22 \%$ & & $16 \%$ & $* * *$ \\
\hline 4th quintile & $22 \%$ & $22 \%$ & & $6 \%$ & $* * *$ \\
\hline 5th quintile & $21 \%$ & $20 \%$ & $*$ & $2 \%$ & $* * *$ \\
\hline Population density (1,000 per sq. mi.) (mean) & 4.3 & 4.4 & & 5.2 & $* * *$ \\
\hline Population density (1,000 per sq. mi.) (median) & 1.8 & 2.1 & $* * *$ & 2.2 & $* * *$ \\
\hline Regional transit accessibility z-score (mean) & -0.06 & -0.08 & $* * *$ & 0.09 & $* * *$ \\
\hline Regional transit accessibility z-score (median) & -0.36 & -0.36 & $* * *$ & -0.31 & $* * *$ \\
\hline No transit data available for home census tract & $42 \%$ & $39 \%$ & $* * *$ & $44 \%$ & $* * *$ \\
\hline Family lives in a rural area & $4 \%$ & $4 \%$ & & $3 \%$ & \\
\hline
\end{tabular}

Note: Stars indicate significant difference from those born before 1980

Stars are: * for $p<.05, * *$ for $p<.01$, and *** for $p<.001$

We begin with a naïve model, in which we assume that the only difference between Millennials and non-Millennials is their birth cohort. This is the starting point for much of the popular and scholarly discussion around Millennials' lower levels of car ownership. Our model affirms these large differences between Millennials and the earlier cohorts, as well as differences between economically dependent and independent Millennials. As shown in Model 1 in Table 2, when we only control for survey year and economic dependence among Millennials, economically dependent Millennials are expected to own far fewer cars per adult in the family -12 percent fewer $\left(\mathrm{e}^{-0.13}=0.88\right)$ 
than other generations, and economically independent Millennials have even fewer cars per adult $\left(\mathrm{e}^{-0.13-0.02}=-14\right.$ percent $)$. Figure 7 shows the results graphically for economically dependent and independent Millennials for this naïve model along with the subsequent models described below.

In our second model, we add age and its squared term to allow the age effects to follow the curve observed in Figure 1, with car ownership (again, per adult) peaking in the middle of one's adult years. Simply by accounting for the fact that Millennials are young during our study period, we can account for the majority of the "Millennial effect" on car ownership. In this model, there are no significant differences between economically dependent Millennials and older cohorts. The difference between economically independent Millennials and older cohorts also diminishes, though some difference remains; economically independent Millennials are expected to have five percent fewer cars per adult than would be expected, given their age.

In the third model, we drop the age variables and add in racial/ethnic characteristics of the family head as controls, accounting for the fact that Millennials are more likely to be people of color than are previous generations. While we observe very meaningful differences between racial/ethnic groups (all non-white groups have considerably lower access to cars than do whites), simply accounting for racial and ethnic diversity explains little of Millennials' lower car ownership rates.

Substituting in our socio-economic variables (income, wealth, and family composition) as controls in our model, we find that the "Millennial effect" reverses for economically independent Millennials, but not for other Millennials. This model suggests that economically independent Millennials have a 3 percent higher car to adult ratio than 
older generations would have had, given Millennials' precarious economic status. We also observe meaningful and statistically significant effects of income and wealth. Higher-income and wealthier families are far more likely to own more cars. The model suggests that wealth's impact on car ownership is non-linear; the wealthiest 80 percent of families own far more cars than the least-wealthy 20 percent, though among the wealthier majority, the differences are relatively small.

Our fifth and sixth models substitute in attributes about the census tract where the family lives. Model 5 adds population density (1,000s of persons per square mile) and a dummy variable indicating whether the family lives in rural area. The addition of these variables decreases the "Millennial effect" for Millennials who have moved away from home, though the difference in effect size is minor. When controlling for the fact that Millennials live, on average, in denser neighborhoods, we find that they own still fewer cars than when we do not control for neighborhood characteristics.

Model 6 substitutes in our measures of access to jobs by transit. Adding these variables does not appreciably change the "Millennial effect," though families that live in areas with excellent transit access own fewer cars, as we would expect. Those who live in areas where we had no transit data have more cars. We suspect that this variable functions as a proxy for places with little or no transit access, though we cannot be sure of this. Our results were similar when we used multiple imputation methods to address the missing data and when omitted cases with missing data. 
Table 2 Random-effects Poisson model of number of cars, PSID 1999-2013

\begin{tabular}{|c|c|c|c|c|c|c|c|}
\hline & Model 1 & Model 2 & Model 3 & Model 4 & Model 5 & Model 6 & Model 7 \\
\hline \multicolumn{8}{|l|}{ Age } \\
\hline Millennial (Born in 80s or 90s) & $-0.13 * * *$ & 0.00 & $-0.10 * * *$ & $-0.14 * * *$ & $-0.13 * * *$ & $-0.13 * * *$ & $-0.13 * * *$ \\
\hline Millennial, econ. indepdenent & $-0.02 * * *$ & $-0.05 * * *$ & $-0.03 * * *$ & $0.17 * * *$ & $-0.01 * *$ & 0.00 & $0.14 * * *$ \\
\hline Age & & $0.01 * * *$ & & & & & $0.01 * * *$ \\
\hline Age (squared) & & $-0.0001 * * *$ & & & & & $-0.0001 * * *$ \\
\hline \multicolumn{8}{|c|}{ Race/Ethnicity of family head (base is Non-Hispanic white) } \\
\hline Non-Hispanic black & & & $-0.40 * * *$ & & & & $-0.22 * * *$ \\
\hline Non-Hispanic Asian & & & $-0.26 * * *$ & & & & $-0.18 * * *$ \\
\hline Non-Hispanic other & & & $-0.14 * * *$ & & & & $-0.09 * * *$ \\
\hline Latino & & & $-0.31 * * *$ & & & & $-0.15 * * *$ \\
\hline Total family income (logged) & & & & $0.10 * * *$ & & & $0.09 * * *$ \\
\hline Num. employed family members & & & & 0.000 & & & $-0.001 *$ \\
\hline Num. of children in family & & & & 0.000 & & & $-0.001 *$ \\
\hline \multicolumn{8}{|l|}{ Wealth quintiles (Base is 1st quintile) } \\
\hline 2nd quintile & & & & $0.25 * * *$ & & & $0.23 * * *$ \\
\hline 3rd quintile & & & & $0.33 * * *$ & & & $0.29 * * *$ \\
\hline 4th quintile & & & & $0.39 * * *$ & & & $0.34 * * *$ \\
\hline 5 th quintile & & & & $0.42 * * *$ & & & $0.37 * * *$ \\
\hline Family lives in a rural area & & & & & $0.08 * * *$ & & $0.07 * * *$ \\
\hline Population density $(1,000$ per sq. $\mathrm{m}$ & & & & & $-0.02 * * *$ & & $-0.01 * * *$ \\
\hline Regional transit accessibility z-scor & & & & & & $-0.15 * * *$ & $-0.05 * * *$ \\
\hline No transit data available for home & nsus tract & & & & & $0.15 * * *$ & $0.07 * * *$ \\
\hline \multicolumn{8}{|c|}{ Survey year variables (Base is 1999) } \\
\hline 2001 & $0.02 * * *$ & $0.02 * * *$ & $0.02 * * *$ & $0.01 * * *$ & $0.02 * * *$ & $0.02 * * *$ & $0.01 * * *$ \\
\hline 2003 & $0.04 * * *$ & $0.03 * * *$ & $0.04 * * *$ & $0.03 * * *$ & $0.03 * * *$ & $0.04 * * *$ & $0.03 * * *$ \\
\hline 2005 & $0.02 * * *$ & $0.00 * *$ & $0.03 * * *$ & $0.01 * * *$ & $0.01 * * *$ & $0.02 * * *$ & $0.01 * * *$ \\
\hline 2007 & $0.06 * * *$ & $0.04 * * *$ & $0.07 * * *$ & $0.04 * * *$ & $0.05 * * *$ & $0.05 * * *$ & $0.05 * * *$ \\
\hline 2009 & $0.06 * * *$ & $0.03 * * *$ & $0.07 * * *$ & $0.06 * * *$ & $0.04 * * *$ & $0.05 * * *$ & $0.06 * * *$ \\
\hline 2011 & $0.03 * * *$ & 0.00 & $0.04 * * *$ & $0.04 * * *$ & $0.02 * * *$ & $0.03 * * *$ & $0.05 * * *$ \\
\hline 2013 & $0.03 * * *$ & $-0.01 * * *$ & $0.04 * * *$ & $0.03 * * *$ & $0.02 * * *$ & $0.02 * * *$ & $0.04 * * *$ \\
\hline Constant & $-0.05 * * *$ & $-0.40 * * *$ & $0.02 * * *$ & $-1.47 * * *$ & $0.02 * * *$ & $-0.13 * * *$ & $-1.38 * * *$ \\
\hline $\ln ($ alpha $)$ & $-2.5 * * *$ & $-2.50 * * *$ & $-2.85 * * *$ & $-3.10 * * *$ & $-2.80 * * *$ & $-2.66 * * *$ & $-3.68 * * *$ \\
\hline Number of observations & 109,511 & 109,511 & 109,511 & 109,511 & 109,511 & 109,511 & 109,511 \\
\hline Number of observations per group & 22,287 & 22,287 & 22,287 & 22,287 & 22,287 & 22,287 & 22,287 \\
\hline Ave. years of data & 4.91 & 4.91 & 4.91 & 4.91 & 4.91 & 4.91 & 4.91 \\
\hline Chi-squared & 8,280 & 10,724 & 63,024 & 110,000 & 48,566 & 32,487 & 190,000 \\
\hline Log likelihood & $-3,118,018$ & $-3,116,792$ & $-3,092,442$ & $-3,069,683$ & $-3,093,459$ & $-3,105,206$ & $-3,033,240$ \\
\hline
\end{tabular}

Note: Significance stars are: $*$ for $p<.05, * *$ for $p<.01$, and $* * *$ for $p<.001$ 
Finally, model 7 combines all the above variables into one preferred model. Here, we find that Millennials who are economically dependent on others (mostly, their parents) have considerably fewer cars (12 percent fewer) per adult than previous cohorts did. However, we find that those Millennials who are economically independent own slightly more cars (one percent more) than we would expect given their income, wealth, and other factors. We find that the control variables perform as expected, though the inclusion of all variables dampens some of our findings in the "naïve" models (1 through 6). For instance, racial and ethnic differences are dampened somewhat, likely because of the inclusion of wealth and income variables in the final model.

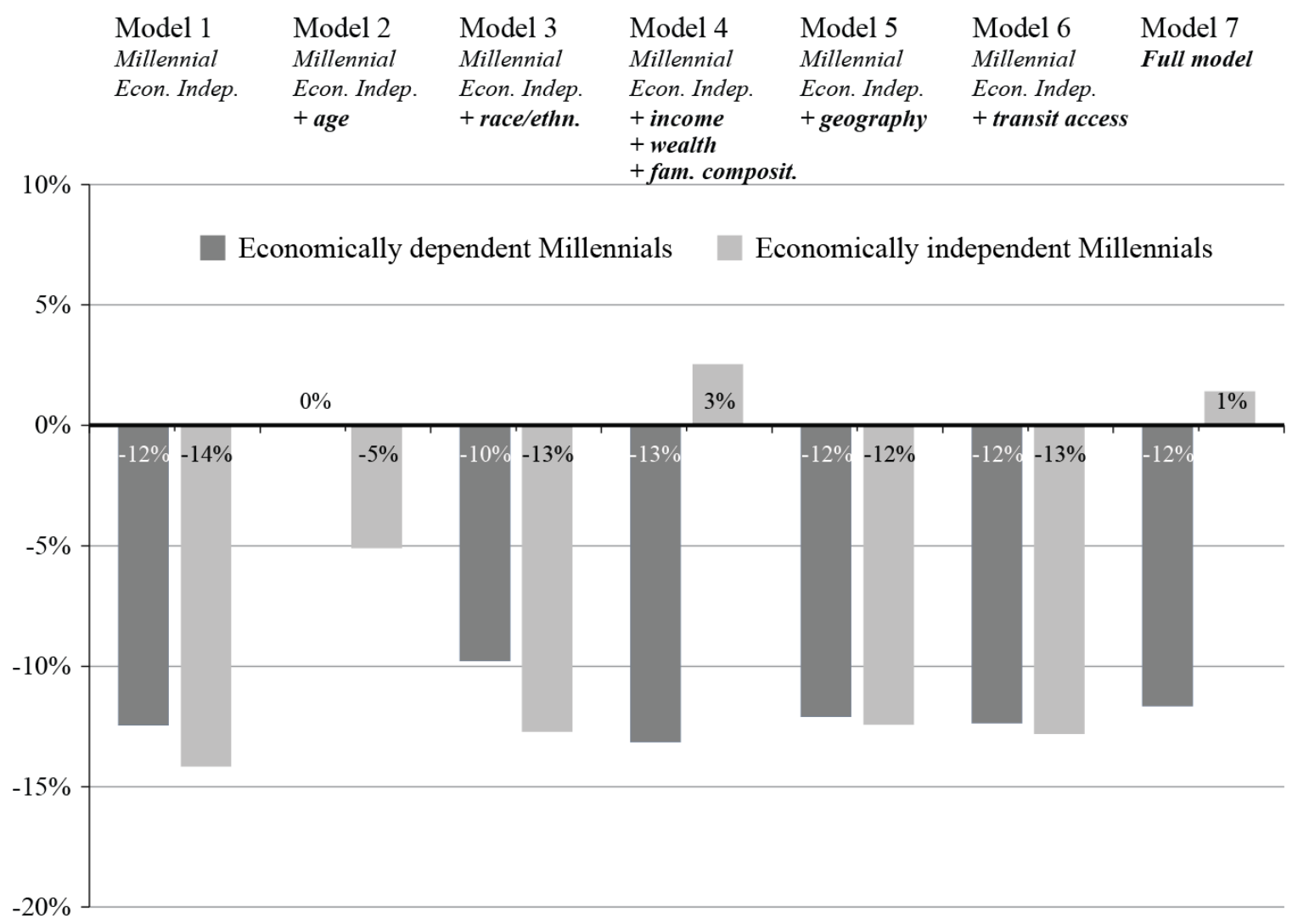

Figure 7 Residual Effect of Millennial Birth Cohort on Car Ownership per Adult in the Family, PSID 1999-2013 


\subsubsection{Alternative model specifications}

In addition to the above models, we tested a series of alternative model specifications. First, we estimated a series of fixed-effects models to control for unobserved characteristics about the individual (these are presented in the Appendix). We ran one model where we interacted Millennial status with age (and age squared), a segmented model where we compared Millennials with older cohorts, and a segmented model comparing economically dependent Millennials, economically independent Millennials and older cohorts. The results for all the models were generally consistent in terms of the direction of effects and their statistical significance with our findings from the random-effects model, though effect size is muted. The non-segmented model predicts, for instance, that economically independent Millennials would own more cars per adult than would non-Millennials, if they were similar to those older cohorts in terms of income, wealth, and so on as the older cohorts.

In our segmented models, we observe some notable differences between Millennials and other cohorts. First, we observe a very strong age effect for economically dependent Millennials that is not accounted for by the other variables. The model predicts that Millennials (both independent and dependent) have slightly more cars than we would expect at younger ages, and slightly fewer than we could expect at older ages, controlling for other variables in the model. While the effect of age is stronger for dependent Millennials, the opposite is true for income and wealth, which have a stronger effect for independent Millennials and older cohorts. As they age and transition to economic independence, these models suggest, Millennials' access to cars is significantly dampened by economic factors, by far the most explanatory variables in the model. 
Another notable difference is that the relationship between our transit accessibility measures and car ownership is stronger for all Millennials than older cohorts. While this suggests that Millennials may have a different relationship with transit than older cohorts, the effect of transit access is still relatively minor compared with that of economic factors; a standard deviation increase in transit accessibility is associated with just a 3.5 percent decrease in auto ownership among Millennials, compared with a 1.5 percent decrease for older cohorts.

In addition to these fixed-effects models, we tested alternative specifications for the random-effects models. First, we tested a series of models of families, rather than individuals. In these models, we assigned the age of the head of the family to stand in for the "age" of the family and another where we used the average age of the head and spouse (when a spouse is present) as a proxy for the "age" of the family. A limitation of this approach is that we can only identify Millennials who have left the nest (the economically independent Millennials who have become household heads).

Economically dependent Millennials are subsumed into their parents' families. Using this formulation, we find the differences in car ownership between families headed by Millennials and families headed by older adults are largely explained by the same economic, geographic and family factors that we employ in our models above. However, in contrast to the above models, in this family-head model, we find that some automobile deficit remains for Millennials; the model suggests that families headed by Millennials own, on average, three percent fewer cars per adult than did previous cohorts, controlling for other variables in the model.

We also tested models that relaxed our age restrictions, used decadal age cohorts 
rather than continuous variables, and used different measures of transit access (for instance, quintiles of transit access, using the same data sources). In each case, the results were largely consistent with the preferred models presented above.

\section{DISCUSSION}

Millennials own fewer cars than previous generations. On average, Millennials own about 13 percent fewer cars than families headed by older cohorts. Some have speculated a sea change in preferences is at the heart of these changes. While we do not directly test the changing preferences theory, we do find that Millennials' dire economic situation plays a very large role in these differences. When we control for age and economic factors, we find that only those Millennials who remain economically dependent on their families have unexpectedly low car access, about 12 percent fewer cars per adult. Millennials who have struck it out own their own actually own slightly more cars than we would expect given their low incomes, wealth, and other factors. This suggests that the particular economic factors effecting Millennials-decreased employment, lower incomes and less wealth — explain most of the differences in car ownership between Millennials and older generations.

Of course, habits and preferences do not exist in a vacuum; it is possible that even after Millennials emerge from these dark economic times, some will choose to continue to live in dense urban areas, use transit, and adopt a car-light lifestyle. Yet as our models suggest, geography and transit access explain very little of the difference in Millennials' lower car ownership rates.

Although we find that the dramatic decline in car ownership among younger 
Americans can almost entirely be explained by age and economic factors, others have found persistent effects associated with their use of the car (McDonald, 2015). This may signal a shift; self-supporting Millennials may own as many or more cars as we would expect, given their age and economic conditions, but they may be using those cars less than previous generations. This could be something to celebrate: their lives may enable a car-light lifestyle. Or, it could be something to bemoan: they could be balancing their precarious budgets by avoiding trips they might wish to take. Future research will help to disentangle these explanations - we suspect that, as is often the case, it's "a little of this, a little of that." Policy-makers should focus on supporting those who are balancing their budgets by traveling less, while encouraging those who are reducing their driving by choice.

Our findings are another reminder that transportation choices are largely — though certainly not exclusively_an economic matter. Of course, preferences matter; they can, for instance, lead us to neighborhoods where driving and parking are expensive hassles and transit service is excellent. However, "getting the price right" for travel modes can have a tremendous impact on mode choices. The challenge is to do so without further hurting those who are, unfortunately, already hurting. 


\section{ACKNOWLEDGEMENTS}

We obtained access to the restricted version of the Panel Study of Income Dynamics from the Institute for Social Research at the University of Michigan, Ann Arbor. The collection of data used in this study was partly supported by the National Institutes of Health under grant number R01 HD069609 and the National Science Foundation under award number 1157698. The Brookings Institution and the Accessibility Observatory at the University of Minnesota provided data on job accessibility by public transit. 


\section{REFERENCES}

Blumenberg, E., Taylor, B.D., Smart, M.J., Ralph, K., Wander, M., Brumbaugh, S., 2012. What's youth got to do with it? Exploring the travel behavior of teens and young adults (No. UCTC-FR-2012-14). University of California Transportation Center, Berkeley, CA.

Dal Fiore, F., Mokhtarian, P.L., Salomon, I., Singer, M.E., 2014. "Nomads at last”? A set of perspectives on how mobile technology may affect travel. J. Transp. Geogr. 41, 97-106. doi:10.1016/j.jtrangeo.2014.08.014

Delbosc, A., 2016. Delay or forgo? A closer look at youth driver licensing trends in the United States and Australia. Transportation 1-8. doi:10.1007/s11116-016-9685-7

Delbosc, A., Currie, G., 2013. Causes of Youth Licensing Decline: A Synthesis of Evidence. Transp. Rev. 33, 271-290. doi:10.1080/01441647.2013.801929

Fitzgerald, J.M., 2011. Attrition in Models of Intergenerational Links Using the PSID with Extensions to Health and to Sibling Models. B E J Econ. Anal Policy 11. doi:10.2202/1935-1682.2868

Goodwin, P., 2012. Peak Travel, Peak Car and the Future of Mobility (International Transport Forum Discussion Papers). Organisation for Economic Co-operation and Development, Paris.

Jones, D.W., 2008. Mass motorization + mass transit : an American history and policy analysis. Indiana University Press, Bloomington.

Kuhnimhof, T., Armoogum, J., Buehler, R., Dargay, J., Denstadli, J.M., Yamamoto, T., 2012. Men Shape a Downward Trend in Car Use among Young AdultsEvidence from Six Industrialized Countries. Transp. Rev. 32, 761-779. doi:10.1080/01441647.2012.736426

Kuhnimhof, T., Zumkeller, D., Chlond, B., 2013. Who Made Peak Car, and How? A Breakdown of Trends over Four Decades in Four Countries. Transp. Rev. 33, 325-342. doi:10.1080/01441647.2013.801928

Kurz, C., Li, G., Vine, D., 2016. The Young and the Carless? The Demographics of New Vehicle Purchases (FEDS Notes No. 10.17016/2380-7172.1798). Board of Governors of the Federal Reserve System, Washington.

McDonald, N.C., 2015. Are Millennials Really the "Go-Nowhere" Generation? J. Am. Plann. Assoc. 81, 90-103. doi:10.1080/01944363.2015.1057196

McGonagle, K.A., Schoeni, R.F., Sastry, N., Freedman, V.A., 2012. The Panel Study of Income Dynamics: Overview, Recent Innovations, and Potential for Life Course Research. Longit Life Course Stud 3, 268-284.

Metz, D., 2013. Peak Car and Beyond: The Fourth Era of Travel. Transp. Rev. 33, 255270. doi:10.1080/01441647.2013.800615

Millard-Ball, A., Schipper, L., 2011. Are We Reaching Peak Travel? Trends in Passenger Transport in Eight Industrialized Countries. Transp. Rev. 31, 357-378. doi:10.1080/01441647.2010.518291

Mokhtarian, P., 2009. If telecommunication is such a good substitute for travel, why does congestion continue to get worse? Transp. Lett. 1, 1-17.

Mokhtarian, P.L., 2002. Telecommunications and travel: The case for complementarity. J. Ind. Ecol. 6, 43-57. 
Myers, D., 2016. Peak Millennials: Three Reinforcing Cycles That Amplify the Rise and Fall of Urban Concentration by Millennials. Hous. Policy Debate 0, 1-20. doi:10.1080/10511482.2016.1165722

Owen, A., Levinson, D.M., 2014. Access Across America: Transit 2014 Data [dataset] [WWW Document]. Retrieved Data Repos. Univ. Minn. URL http://dx.doi.org/10.13020/D6MW2Q. (accessed 1.6.15).

Panel Study of Income Dynamics, restricted use data, 2014. . Produced and distributed by the Survey Research Center, Institute for Social Research, University of Michigan.

Polzin, S.E., Chu, X., Godfrey, J., 2014. The impact of millennials' travel behavior on future personal vehicle travel. Energy Strategy Rev., US energy independence: Present and emerging issues 5, 59-65. doi:10.1016/j.esr.2014.10.003

Ralph, K.M., 2015. Stalled on the Road to Adulthood? Analyzing the Nature of Recent Travel Changes for Young Adults in America, 1995 to 2009. University of California, Los Angeles.

Tomer, A., Kneebone, E., Puentes, R., Berube, A., 2011. Missed Opportunity: Transit and Jobs in Metro America. The Brookings Institution, Washington, DC.

TransitCenter, 2014. Who's on board: 2014 mobility attitudes survey. TransitCenter, New York.

U.S. Department of Transportation, 2015. National Transportation Statistics 2015. U.S. Department of Transportation, Bureau of Transportation Statistics, Washington, DC.

USPIRG Education Fund, Frontier Group, 2014. Millennials in Motion: Changing Travel Habits of Young Americans and the Implications for Public Policy.

van Wee, B., 2015. Peak car: The first signs of a shift towards ICT-based activities replacing travel? A discussion paper. Transp. Policy 42, 1-3. 


\section{APPENDIX}

While the random-effects models included in the body of the article are preferable because they allow us to control for time-invariant characteristics such as birth cohort, race/ethnicity and the like, we also estimated a series of fixed-effects models. These are shown in table A1. The first model uses the full sample, while the following three models use non-Millennials, economically dependent Millennials, and economically independent Millennials, respectively. The results of these models largely support the findings of our preferred models; age, income, employment, household structure, and other variables are strong and consistent predictors of car ownership levels.

The fixed-effects models suggest that Millennials' levels of car ownership are surprisingly high given their economic situations, as we demonstrate in figure A1. This figure uses our three population-segmented models and plots the predicted number of cars that a family would own given location in four different levels of transit accessibility: one-half standard deviation below the regional mean, at the regional mean, and one-half and one full standard deviation above the mean. All other variables are held constant (a two-earner household with one child earning a median income, and so forth). As the graph suggests, were Millennials (both economically dependent and independent) to have characteristics similar to prior generations, they would likely own far more cars; in fact, the models suggest they would own even more cars than prior generations did at the same life stage. We similarly used the model employing the full sample to produce these predictions, and the results were nearly identical. 
Table A1. Fixed-effects Poisson models of number of cars, PSID 1999-2013

\begin{tabular}{|c|c|c|c|c|c|c|c|}
\hline & Everyone & & & gmented Moc & dels & & \\
\hline & & Older Cohor & & $\begin{array}{l}\text { Econ. Dep. } \\
\text { Millennials }\end{array}$ & & $\begin{array}{l}\text { Econ. Indep } \\
\text { Millennials }\end{array}$ & \\
\hline Age & $-0.010 * * *$ & -0.006 & & $0.074 *$ & $* * *$ & $0.025 *$ & $* *$ \\
\hline Age (squared) & $-0.0001 * * *$ & -0.0001 & $* * *$ & $-0.003 *$ & $* * *$ & $-0.001 *$ & $* * *$ \\
\hline Age *Millennial & $0.017 * * *$ & & & & & & \\
\hline Age (squared) $*$ Millennial & $-0.0003 * * *$ & & & & & & \\
\hline Head or spouse & $0.027 * * *$ & 0.048 & $* * *$ & & & $-0.108 *$ & $* * *$ \\
\hline Total family income (logged) & $0.028 * * *$ & 0.022 & $* * *$ & $0.007 *$ & $* *$ & $0.026 *$ & *** \\
\hline Num. employed family members & $0.002 * *$ & 0.0004 & & $0.016 *$ & $* * *$ & $0.032 *$ & $* * *$ \\
\hline Num. of children in family & $0.030 * * *$ & 0.029 & $* * *$ & $0.063 *$ & $* * *$ & $0.008 *$ & $* *$ \\
\hline Wealth quintiles (Base is 1st quintile) & & & & & & & \\
\hline 2nd quintile & $0.161 * * *$ & 0.140 & $* * *$ & $0.142 *$ & *** & $0.216 *$ & $* * *$ \\
\hline 3rd quintile & $0.179 * * *$ & 0.158 & $* * *$ & $0.148 *$ & $* * *$ & $0.248 *$ & $* * *$ \\
\hline 4th quintile & $0.202 * * *$ & 0.179 & $* * *$ & $0.153 *$ & $* * *$ & $0.226 *$ & $* * *$ \\
\hline 5th quintile & $0.231 * * *$ & 0.201 & $* * *$ & $0.164 *$ & *** & $0.295 *$ & $* * *$ \\
\hline Population density (1,000 per sq. mi.) & $-0.008 * * *$ & -0.007 & $* * *$ & $-0.010 *$ & *** & $-0.003 *$ & $* * *$ \\
\hline Regional transit accessibility z-score & $-0.030 * * *$ & -0.015 & $* * *$ & $-0.032 *$ & *** & $-0.033 *$ & $* * *$ \\
\hline No transit data available for home census tract & $0.015 * * *$ & 0.011 & $* * *$ & -0.022 & & $0.048 *$ & $* * *$ \\
\hline Survey year variables (Base is 1999) & & & & & & & \\
\hline 2001 & $0.047 * * *$ & 0.037 & $* * *$ & $0.127 *$ & *** & -0.010 & \\
\hline 2003 & $0.095 * * *$ & 0.077 & $* * *$ & $0.223 *$ & *** & $0.102 *$ & $* *$ \\
\hline 2005 & $0.104 * * *$ & 0.077 & $* * *$ & $0.300 *$ & *** & $0.157 *$ & $* * *$ \\
\hline 2007 & $0.170 * * *$ & 0.133 & $* * *$ & $0.448 *$ & $* * *$ & $0.245 *$ & $* * *$ \\
\hline 2009 & $0.210 * * *$ & 0.162 & $* * *$ & $0.555 *$ & $* * *$ & $0.317 *$ & $* * *$ \\
\hline 2011 & $0.226 * * *$ & 0.166 & $* * *$ & $0.639 *$ & $* * *$ & $0.373 *$ & $* * *$ \\
\hline 2013 & $0.257 * * *$ & 0.196 & $* * *$ & $0.734 *$ & $* * *$ & 0.414 * & $* * *$ \\
\hline Number of observations & 103,389 & 77,345 & & 11,457 & & 12,782 & \\
\hline Number of observations per group & 18,613 & 12,461 & & 3,700 & & 3,457 & \\
\hline Ave. years of data & 5.6 & 6.2 & & 3.1 & & 3.7 & \\
\hline Chi-squared & 17,186 & 9,855 & & 1,331 & & 2,645 & \\
\hline Log likelihood & $-1,987,280$ & $-1,608,337$ & & $-163,484$ & & $-154,017$ & \\
\hline
\end{tabular}




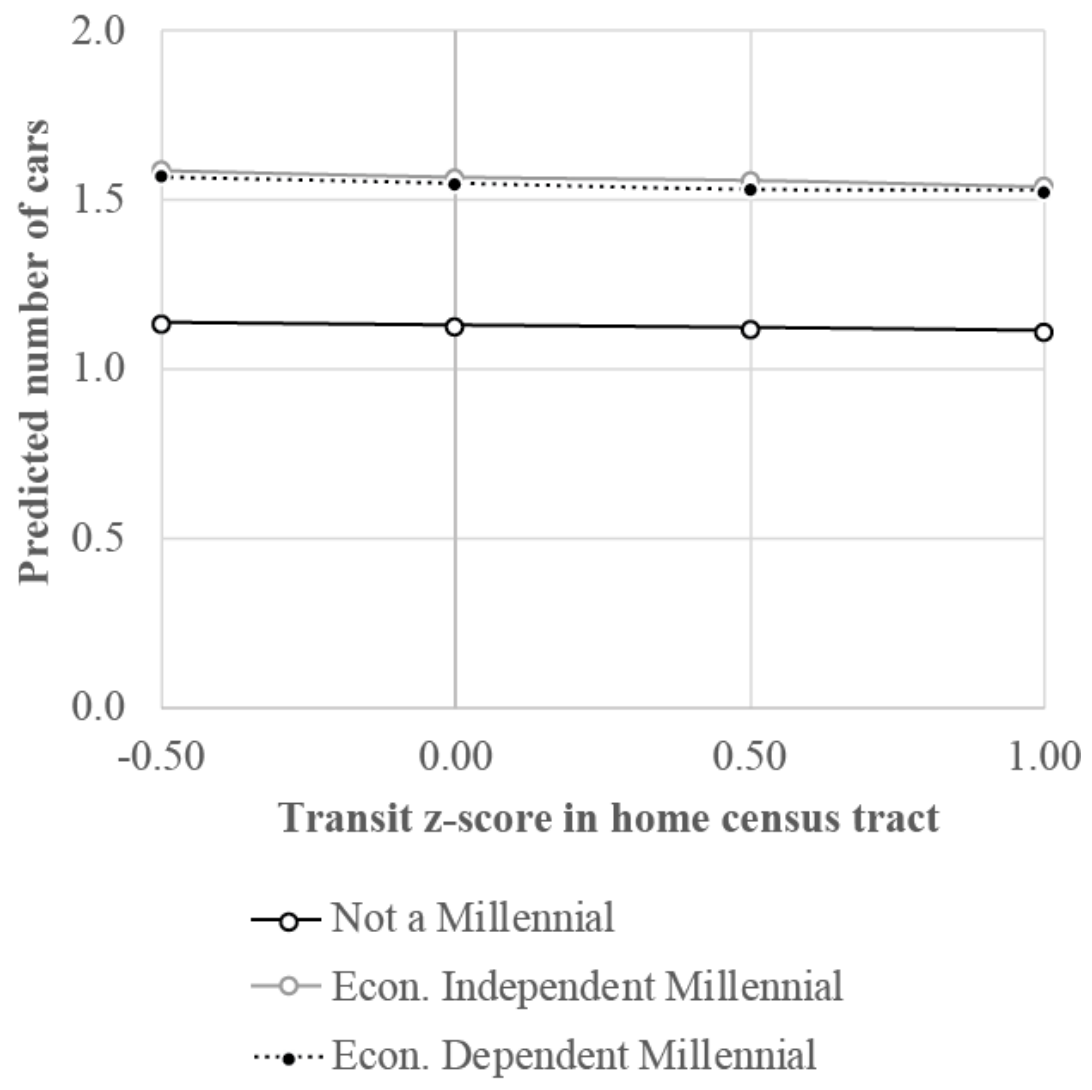

Figure A1. Predicted effect of transit access to jobs on car ownership levels, three models, PSID 1999-2013 